\title{
Awareness and practices on eye effects among people with diabetes in rural Tamil Nadu, India.
}

\author{
Balasubramaniyan $\mathrm{N}^{1}$, Ganesh Kumar S $\mathrm{S}^{2}$, Ramesh Babu K³ , Subitha L ${ }^{2}$
}

1. Public Health Management (PGDPHM) Trainee (JIPMER), Epidemiologist, Villupuram district, Govt.of Tamil Nadu.

2. Preventive and Social Medicine, Jawaharlal Institute of Postgraduate Medical Education and Research (JIPMER), Puducherry, India.

3. Ophthalmology, Jawaharlal Institute of Postgraduate Medical Education and Research (JIPMER)

Puducherry, India.

\begin{abstract}
Background: Recently eye effects of Diabetes Mellitus (DM) are an important concern due to increase in its trend especially in developing countries.

Objectives: To assess the awareness related to eye effects of DM and its prevention practices among people with diabetes.

Methods: This cross sectional study was conducted from January 2013 to April 2013 in Villupuram district of Tamil Nadu, India. All 105 people with diabetes from the service area of two sub-centres were included. Data on socio demographic details, history of DM, awareness on systemic complications of DM, effects of DM on eyes, practice on regular blood check-up, eye examination and source of information were collected by interview technique using a structured questionnaire. Univariate and multiple logistic regression analysis were done to assess the association of awareness of eye examination with socio-demographic variables.

Results: Mean age of the study population was 56.7 years. About 93 people with diabetes $(88.6 \%)$ tested their blood sugar at least once in every 3 months. About 80 people with diabetes $(76.2 \%)$ were aware of at least one systemic complication of DM. Although $78(74.3 \%)$ people with diabetes were aware that DM could affect the eyes, majority of this group $(68,87.2 \%)$ did not know the specific effects of DM on eyes. In this group, about $28(35.9 \%)$ people with diabetes were not aware of the reasons for eye effects, while others mentioned that persistent high blood sugar level $(n=26,33.3 \%)$, longer duration of DM $(n=14$, $17.9 \%)$ and lifestyle $(\mathrm{n}=10,12.8 \%)$ were the reasons for the eye effects of DM. Only $31(29.5 \%)$ of them knew that their eyes must be regularly examined. People with diabetes who had post-secondary and above ( $>10$ th standard) level of education had significantly higher awareness on examination of eye (Adjusted OR=19.63).

Conclusion: Although awareness of people with diabetes on systemic effects of DM was more, their awareness on specific eye effects and need for regular screening was low. Systematic efforts are required to increase awareness on eye effects and importance of regular screening in this population.
\end{abstract}

Key words: Awareness, diabetes, eye effects, India, practice.

DOI: http://dx.doi.org/10.4314/ahs.v16i1.28

Cite as: Balasubramaniyan N, Ganesh KS, Ramesh BK, Subitha L. Awareness and practices on eye effects among people with diabetes in rural Tamil Nadu, India. Afri Health Sci. 2016;16(1): 210-217. bttp:// dx.doi.org/10.4314/ahs.v16i1.28

\section{Introduction}

Diabetic Retinopathy (DR) is the leading cause of blindness in adult age group and affects both the genders equally. In India, by the year 2025 approximately one-fifth to one-third of all persons (57 million) with Diabetes

\section{Corresponding author: \\ Ganesh Kumar S, \\ Preventive and Social Medicine, \\ JIPMER, Puducherry -06 \\ E mail: sssgan@yahoo.com}

Mellitus (DM) will have retinopathy. Among them, approximately 5.7 million people with diabetes will have severe retinopathy and will require either laser or surgical intervention to preserve vision ${ }^{1}$. In view of the above, awareness on eye effects of DM and its prevention is an important pre-requisite for prevention of eye complications.

Routine comprehensive eye evaluation helps to detect early treatable stages of DR which are frequently asymptomatic. Comprehensive eye examination is recommended immediately after diagnosis in DM. People with 
diabetes without evidence of retinopathy should undergo eye examinations every year to detect it at an early stage ${ }^{2}$. The major challenge for eye care programmes will be to ensure regular follow-up examinations of persons with $\mathrm{DM}$ and compliance to repeat examination. There is a need to understand the dangers of missing ophthalmic examinations among people with diabetes ${ }^{3}$. But, these are often poorly understood by them and their relatives. In such situation, improving their awareness leveltowards eye care is vital to achieve goals of Vision 2020 program for eliminating avoidable blindness ${ }^{4}$.

However, there is a paucity of data with regard to awareness and practice on eye effects of DM among people with diabetes in this part of India. With this background, the present study was conducted to determine the awareness and practice on eye effects of DM among people with diabetes in rural Tamil Nadu, India.

\section{Materials and methods Study setting}

This cross sectional study was carried out during January 2013 to April 2013 in two sub centre areas namely Pakkam and Mandagapattu, belonging to Kondur Primary Health Centre (PHC) of Kandamangalam Block, Villupuram, Tamil Nadu.

\section{Ethical issues}

The study was approved by the scientific committee and ethics committee of the institute.Written permission was obtained from the Deputy Director of Health Services (DDHS) Villupuram Health Unit District (HUD). Written informed consent was obtained from the study subjects. Incase of illiterate subjects, consent was obtained from the immediate care givers.

\section{Sample size estimation and sampling technique}

The sample size was calculated as 104 based on 30\% level of awareness regarding diabetic retinopathy in earlier Indian studies ${ }^{5}$ and $30 \%$ relative precision. Two sub-centre areas were chosen out of seven centres by simple random technique. List of all people with diabetes attending chronic disease clinic at these sub-centres was compiled.
There were 105 people with diabetes in these 2 subcentre areas attached to Primary Health Center (PHC) Kondur and all of them were included in the study.

\section{Method of data collection}

Data was collected by the investigator through house to house surveys by interview technique using a structured questionnaire. The questionnaire was a KAP (Knowledge, Attitude and Practice) type of questionnaire.The questionnaire was translated into the local language Tamil and back translated into English. The face validity of the questionnaire was established through consultation with a panel of experts. The investigator was trained in the administration of the questionnaire to the people with diabetes, and responses were noted verbatim. The questionnaire was not administered to people without diabetes as controls. Study parameters that include socio demographic details, details on history of DM and awareness on systemic complications of DM were collected. Details on awareness of various eye effects of DM, practice on regular blood check-up, eye examination and source of information were also collected.

\section{Statistical analysis}

All categorical data was analyzed using proportion and chi-square test. Multiple logistic regression analysis was done to assess the association of awareness of eye examination with socio-demographic variables. Statistical analysis was done at 5\% level of significance using Statistical Package for Social Sciences(SPSS) version 19.

\section{Results}

A total of 105 people with diabetes participated in the study. The mean age of the study population was 56.7 years, and proportion of females who participated in the study was $56 \%$. About $47(44.8 \%)$ people with diabetes were more than 60 years of age followed by 44(41.9\%) in the age group 45-59 years. About $59(56.3 \%)$ of people with diabetes had $\mathrm{n}$ o formal education and about $39(37.1 \%)$ belonged to unskilled occupation.

All the study participants were on oral hypoglycemic agents and majority of them had compliance to medication. Details regarding history of Diabetes Mellitus among study population is given in Table 1. 
Table 1: Details regarding history of Diabetes Mellitus a mong study population ( $n=105)$

\begin{tabular}{|l|c|c|}
\hline CHARACTERISTICS & FREQUENCY & $\%$ \\
\hline DURATION OF DM (IN YEARS) & 11 & 10.5 \\
$1-5$ & 63 & 60.0 \\
$6-8$ & 15 & 14.3 \\
$\geq 9$ & 16 & 15.2 \\
& & \\
FAMILY HISTORY OF DM & 39 & 37.1 \\
Yes & 66 & 62.9 \\
No & & 59.0 \\
\hline COEXISTING HYPERTENSION & 62 & 41.0 \\
Yes & 43 & 89.5 \\
No & & 10.5 \\
\hline COMPLIANCE TO TREATMENT & 94 & \\
Regular & 11 & \\
Dose missed in previous month & & \\
\hline
\end{tabular}

Three fourths of people with diabetes were aware of atleast one systemic complications of DM. Details of awareness on complication and management of DM was given in Table 2.

Table 2: Details regarding awareness on complications of $D M$ and its management among patients with diabetes $(\mathrm{N}=105)$

\begin{tabular}{l|l|l|}
\hline $\begin{array}{l}\text { Awareness } \\
\text { components }\end{array}$ & Yes n(\%) & No n (\%) \\
\hline $\begin{array}{l}\text { Systemic } \\
\text { Complications } \\
\text { Of Diabetes }\end{array}$ & $80(76.2)$ & $25(23.8)$ \\
\hline $\begin{array}{l}\text { Diabetes } \\
\text { fffects eye }\end{array}$ & $78(74.3)$ & $27(25.7)$ \\
\hline $\begin{array}{l}\text { Need For Regular } \\
\text { Eye Examination }\end{array}$ & $31(29.5)$ & $74(70.5)$ \\
\hline $\begin{array}{l}\text { Treatment Of } \\
\text { Diabetic } \\
\text { Retinopathy }\end{array}$ & $5(4.8)$ & \\
\hline
\end{tabular}

But regarding awareness of eye examination, only 31 $(29.5 \%)$ knew that their eyes must be regularly examined and only nine of them $(8.6 \%)$ were aware of the correct frequency of eye examinations as at least once in a year. Their main source of information for eye ex- amination was media (52\%), followed by doctor of the Primary Health Centre(PHC) $(39 \%)$, relatives $(6 \%)$ and Village Health Nurse ( VHN) (3\%). Awareness on examination of eye was significantly less among elderly and those with lesser education level [Table 3]. 
Table 3: Association of awareness on eye examination with age, sex and education level

\begin{tabular}{|c|c|c|c|}
\hline Variables & $\begin{array}{l}\text { Number of } \\
\text { subjects }\end{array}$ & $\begin{array}{c}\text { Awareness } \\
\text { examination } \\
(\%)\end{array}$ of $\begin{array}{c}\text { on } \\
\text { eye }\end{array}$ & $\mathbf{X}_{2}, \mathbf{p}$ value \\
\hline \multicolumn{4}{|l|}{ Age group (years) } \\
\hline $30-44$ & 14 & $5(35.7)$ & $9.037,0.011 *$ \\
\hline $45-59$ & 44 & $19(43.2)$ & \\
\hline$\geq 60$ & 47 & $7(14.9)$ & \\
\hline \multicolumn{4}{|l|}{ Gender } \\
\hline Male & 46 & $14(30.4)$ & $0.033,0.857$ \\
\hline Female & 59 & $17(28.8)$ & \\
\hline \multicolumn{4}{|l|}{ Educational status** } \\
\hline No formaleducation & 59 & $14(23.7)$ & $22.158,0.000 *$ \\
\hline $1_{\text {st }}-5$ th standard(Primary) & 19 & $1(5.3)$ & \\
\hline $\begin{array}{l}6_{\text {th }} \text { to } 10_{\text {th }} \text { standard } \\
\text { (Secondary) }\end{array}$ & 19 & $9(474)$ & \\
\hline $\begin{array}{l}>10_{\text {th }} \text { standard(Post- } \\
\text { secondaryandabove) }\end{array}$ & 8 & $7(87.5)$ & \\
\hline \multicolumn{4}{|l|}{ Duration of diabetes } \\
\hline$\leq 5$ years & 74 & $53(71.6)$ & $0.931,0.335$ \\
\hline$>5$ years & 31 & $25(80.6)$ & \\
\hline
\end{tabular}

* pvalue $<0.05, * *$ International Standard Classification Of Education by UNESCO, 1997

Multiple logistic regression analysis showed that people with diabetes with post-secondary and above $(>10$ th standard) level of education had significantly higher awareness on examination of eye. (Adjusted OR=19.63) [Table 4].

Table 4: Association of awareness on eye examination: Multiple Logistic Regression Analysis

\begin{tabular}{|l|c|c|}
\hline Variables & Odds Ratio (95\% CI) & p value \\
\hline Age group (in years) & $1.27(0.28-6.30)$ & 0.769 \\
$30-44$ & $2.49(0.81-7.61)$ & 0.110 \\
$45-59$ & - & - \\
$\geq 60$ & $0.68(0.22-2.04)$ & 0.485 \\
\hline Gender & - & - \\
Male & $19.63(1.77-217.46)$ & $0.015 *$ \\
Female & $2.86(0.82-9.94)$ & 0.099 \\
\hline Educational status ** & $0.18(0.02-1.49)$ & 0.111 \\
$>10$ th standard (Post-secondary & & \\
& & \\
& & \\
\end{tabular}

Among the systematic complications, major- that kidneys could be involved; chest pain (18\%), paity $(74.3 \%)$ had responded that eyes could be affected ralysis $(15 \%)$, nerve damage $(13 \%)$, hypertension $(13 \%)$, due to DM, while nearly half of them $(46.7 \%)$ knew stroke $(6.7 \%)$ and amputation $(5 \%)$ were the other complications regarding which they were aware of [Figure 1]. 
Figure 1: Awareness of systemic complications of DM among the people with diabetes in the study population ( $\mathrm{n}-105$ )

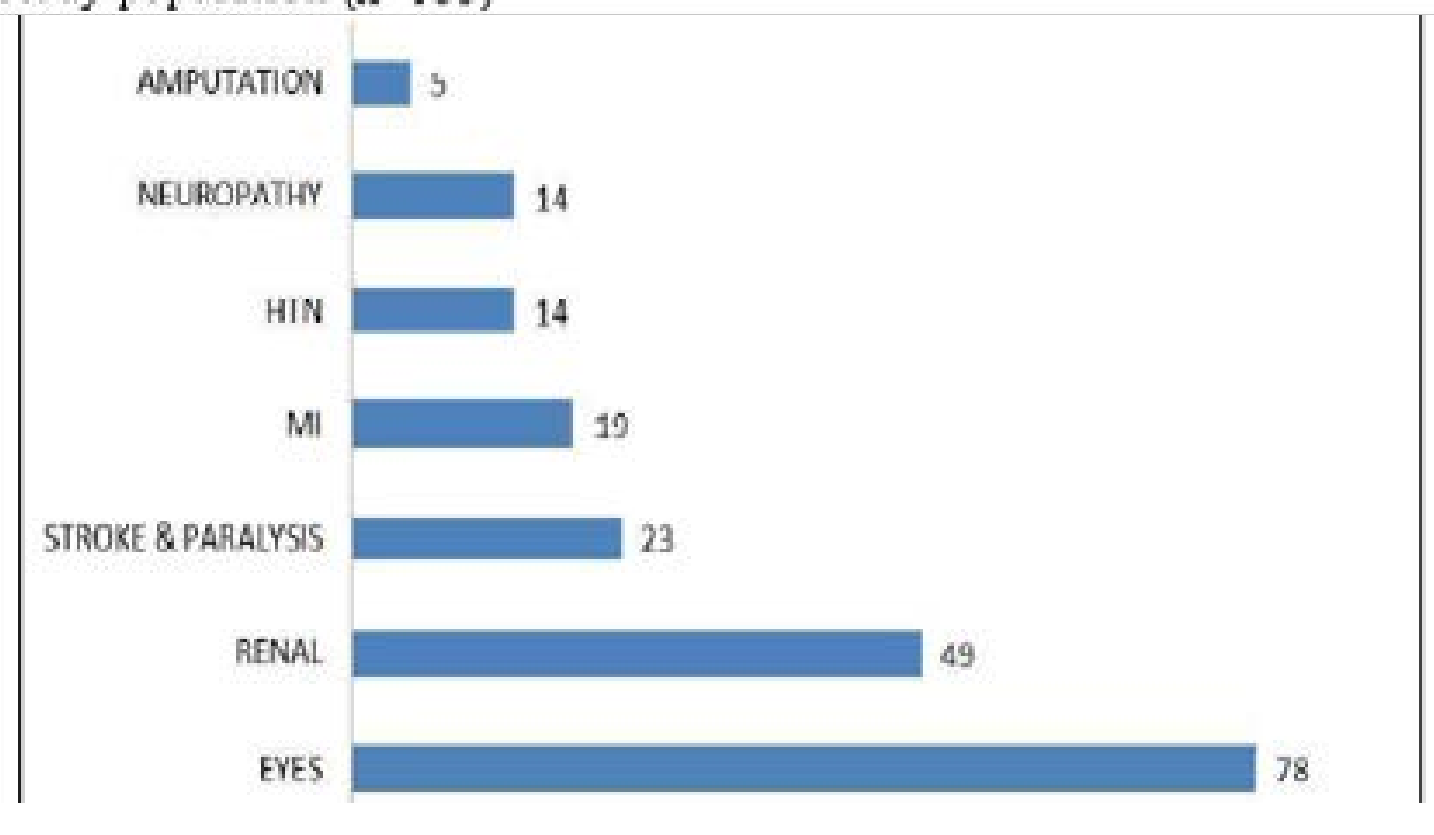

* HTN Hypertension, MI myocardial infarction

About 88.6\% tested their blood sugar at least once in ev- every two months and three months in 39\% and 32.4\% ery 3 months. Frequency of blood sugar testing was once of people with diabetes respectively. [Figure 2].

Figure 2: Frequency of blood test done among patients with diabetes $(n=105)$

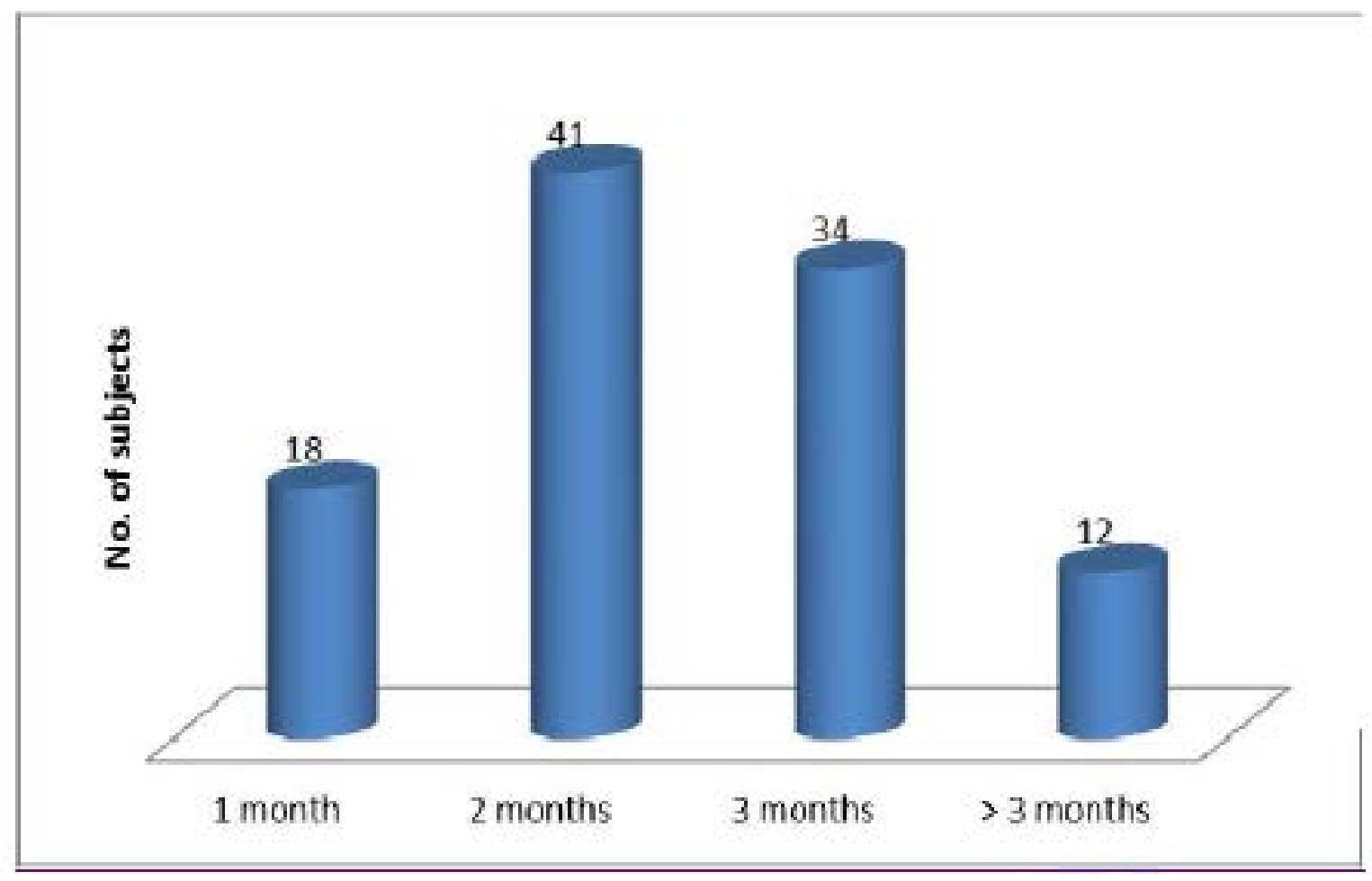


Among 89 people with diabetes who had difficulty in vision, only $48(53.9 \%)$ visited an eye hospital. Self- motivation was the common reason for visiting the eye hospital followed by others [Figure 3].

\section{Figire 3. Sinurce of inform ation on hoşital visit among those who developedvision problems and vatedeye hospital $(\mathrm{N}=48$ )}

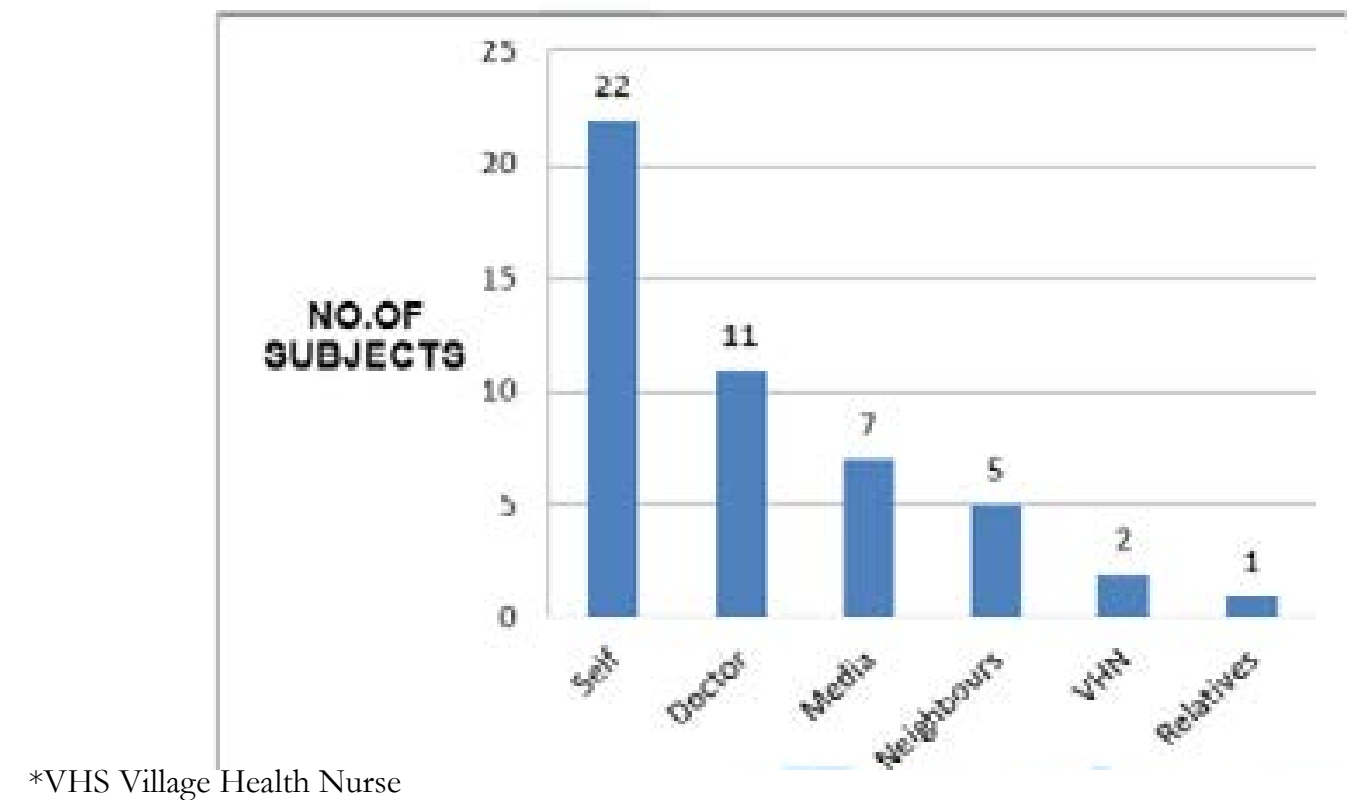

About half of them $(50 \%)$ went to nearby private eye hospitals, $13(27 \%)$ went to eye camps, 11(23\%) attended nearby Government hospitals. Out of the 105 subjects, about $27(25.7 \%)$ were not aware that DM could affect their eyes.
Among the 78 people with diabetes who aware that eyes could be affected as a complication of DM, $3(4.3 \%)$ were aware about cataract and $7(9.0 \%)$ of them knew that diabetic retinopathy (nerve damage) can occur as eye complications; $68(87.2 \%)$ were not aware of the specific effects on the eye. [Figure 4].

Figure 4: Awareness regarding eye effects due to DW athong the study population (n=105)

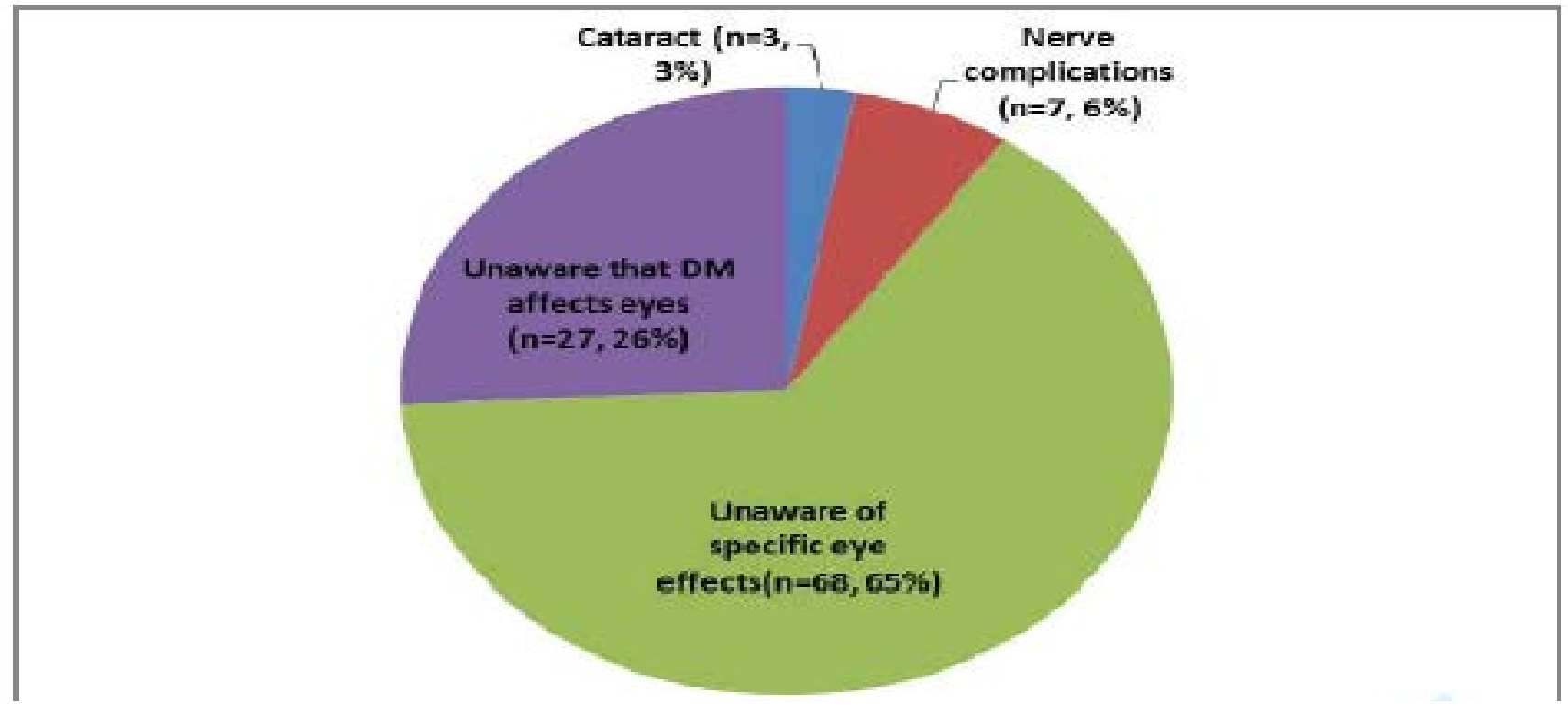


Among 5 people with diabetes who had previous history of DR, all knew that it could affect the eyes, but only one of them knew that DR can occur as an eye complication. Regarding reasons for eye effects of DM, 28 (35.9\%) were not aware of any reasons, while others responded that it was due to persistent high blood sugar level $(n=26,33.3 \%)$, longer duration of DM ( $n=14,17.9 \%)$ and lifestyle $(\mathrm{n}=10,12.8 \%)$. Regarding treatment options available for DR, only 5 (4.7\%) knew that Laser is a method of choice.

\section{Discussion}

The present study highlighted the fact that though people with diabetes were aware of the general effects of DM, their awareness on specific eye effects and need for regular screening was low. Data from our study suggests that a lot of effort is required to increase awareness regarding eye effects in this population and to transform this increased awareness to actual utilization of services. Although recommendations and guidelines for screening people with diabetes exist,studies have shown that such recommendations are not always adhered to, even in the developed world ${ }^{6}$. Delivering ophthalmic care at the appropriate time to people with diabetes can provide eye care programmes with huge cost savings besides reducing the personal suffering caused by blindness and vision impairment ${ }^{7}$.

Various studies have shown different findings at country and global level. The awareness of DR in a study was found to be $29 \%$, need for regular eye examinations as $57 \%$ and role of laser in preventing visual loss as $17 \%$ which are comparatively higher than our study ${ }^{5}$. Other studies reported that the level of awareness about eye complications due to DM was $72 \%$ in $\mathrm{Oman}^{4}, 96 \%$ in Australia ${ }^{8}, 52 \%$ in USA $^{9}$ and $98 \%$ observed in Ja$\operatorname{pan}^{10}$. Recent study from Theni, south India showed it as $50 \%{ }^{3}$. Although majority of the people with diabetes in our study were aware that diabetes effects eyes, they could not report specific eye effects of diabetes. High literacy rates and proactive counseling in other countries and illiterate people with diabetes in our study could be the reasons for this difference.

The level of awareness in relation to treatment for eye complications of DM using Laser was excellent in Oman study ${ }^{4}$. Another study in India also reported that only $10 \%$ of the people with diabetes knew about Laser treatment of diabetes ${ }^{3}$. our study shows less than $5 \%$ in this aspect. Around $57 \%$ of participants had visited ophthalmologists in Myanmar study ${ }^{11}$. Our study showed that people with diabetes who had difficult vision, about $53.9 \%$ visited an eye doctor. More than $80 \%$ were aware of eye examination in Theni study, South India $^{3}$ compared to only $30 \%$ in our study.

DR is a major public health problem and with an ongoing pandemic of DM this problem will get aggravated further in the years to come. Despite effective treatments being available, DR still remains the major cause of preventable vision loss worldwide. Management program for DR from a public health perspective should ideally include timely eye examinations as recommended by World Health Organization (WHO) and other professional bodies, provision of standard preventive treatment, optimal treatment of blood sugar and blood pressure levels, efforts to educate patients with diabetes about eye health and ultimately efforts to prevent DM by educating and empowering them for self-management.

Awareness campaigns to increase the level of awareness on eye complications of DM need to focus on eye effects, regularity of eye examination, availability of treatment and methods for controlling DR. Such campaigns are excellent support mechanisms to increase the utilisation of diabetic eye screening camps. Community participation is the key to success for any awareness or screening model. Appropriate eye health educationthrough diabetic clinics may encourage people at risk to seek timely and appropriate care. This will require developing educational materials that are regionally, linguistically and culturally appropriate, with a good understanding of current knowledge, attitudes and practices in the community. Utilizing the large paramedical forces available in the country for health education may ensure wider coverage and accessibility ${ }^{3}$.

\section{Conclusion}

Although awareness of people with diabetes on systemic effects of DM was more, their awareness on specific eye effects and need for regular screening was low. A lot of effort is required to increase awareness regarding eye effects of DM in this population and transform this to utilization of services. Appropriate eye health education activities in diabetic clinics may help patients with diabetes to seek timely and appropriate care. 


\section{Conflict of interest}

None

\section{Contribution details}

BN: Concept, Design, Literature review, data collection, data entry, report writing, statistical analysis, manuscript writing and editing

GK: Concept, Design, Statistical analysis, Manuscript writing and editing

RBK: Concept, Design, manuscript writing Manuscript writing and editing

SL: Design, Literature review, manuscript writing and Editing.

\section{Acknowledgement}

We thank National Rural Health Mission (NRHM) Director, Government of Tamil nadu, Deputy Director of Health Services (DDHS) Villupuram district, the staff concerned in the Primary Health Center, Kondur and all the subjects participated in the study.

\section{References}

1. Narendran V, John RK, Raghuram A, Ravindran RD, NirmalanPK, Thulasiraj RD. Diabetic retinopathy among self reported diabetics in southernIndia: a population based assessment. Br JOphthalmol.2002;86:1014-18.

2. Yam J, Kwok A. Update on the treatment of diabetic retinopathy. Hong Kong Med J. 2007;13:46-60.

3. Namperumalsamy P, Kim R, Kaliaperumal K, Sekar A,Karthika A, Nirmalan PK. A pilot study on awareness ofdiabetic retinopathy among non-medical persons in South India. Thechallenge for eye care programmes in the region. Indian J Ophthalmol 2004; 52:247-51.
4. Rajiv Khandekar, Saleh Al Harby, Harith Al Harthy, Jawad Al. Lawatti.Knowledge, attitude and practice regarding eye complicationsand care among Omani persons with diabetes - A cross sectional study. Oman J Ophthalmol 2010;3:60-65.

5. Rani P, Raman R, Agarwal S, Paul PG, Uthra S, Margabandhu $G$ et al. Diabetic retinopathy screening model for rural population: awarenessand screening methodology. Rural and Remote Health 2005;5: 350-55.

6. Moss S E, Klein R, Klein B E. Factors associated with eye examinationsin persons with diabetes. Invest Ophthalmol Vis Sci 1994;35:1141.

7. Javitt JC, Aiello LP, Chiang Y, Ferris FL 3rd, Canner $\mathrm{JK}$, Greenfield S.Preventive eye care in people with diabetes is cost saving to thefederal government: implications for health care reform. Diab Care1994;17:909-17.

8. Schmid KL, Schmid LM, Pedersen C. Knowledge of the ocular effects ofdiabetes among the general population of Australia and the membersof Diabetes Australia. Clin Exp Optom 2003;86:91-103.

9. Munoz B, O’Leary M, Fonseca-Becker F, Rosario E, Burguess I, Aquilar M et al. Knowledge of diabetic eye disease and vision care guidelines among Hispanic individuals in Baltimore with and without diabetes. Arch Ophthalmol 2008;126:968-74.

10. Funatsu H, Hori S, Shimizu E, Nakamura S. Questionnaire survey onperiodic ocular examination in Japanese diabetic patients. Am JOphthalmol 2003;136:955-57. 11. Muecke JS, Newland HS, Ryan P, Ramsay E, Arung M, Myint $S$ et al.Awareness of diabetic eye disease among general practitioners and diabetic patients in Yangon, Myanmar. Clin Experiment Opbthalmol 2008;36:265-273. 